\title{
How to impart scientific knowledge and writing skills? Digital education in the COVID-19 pandemic
}

Ann-Kathrin Rauch ( $\square$ ann-kathrin.rauch@uniklinik-freiburg.de )

University of Freiburg

Christian Offergeld

University of Freiburg

Manuel Christoph Ketterer

University of Freiburg

\section{Research Article}

Keywords: data literacy in medicine, digital education, scientific education, competence-based education, Covid-19 pandemic

Posted Date: July 21 st, 2021

DOl: https://doi.org/10.21203/rs.3.rs-724472/v1

License: (c) (i) This work is licensed under a Creative Commons Attribution 4.0 International License. Read Full License 


\section{Abstract}

Introduction

In order to make a virtue out of necessity by establishing a digital teaching curriculum in ORL during the Covid-19 pandemic, we created the concept of a new digital scientific seminar. In this study, we present the students' evaluation of the seminar focusing on digital and scientific skills acquisition.

Methods

We included 265 students in our prospective monocentric questionnaire study. The seminar started with an introduction on the criteria of a good publication, followed by the individual task of understanding the publication on a main ORL topic and writing its abstract. After the seminar students completed the evaluation questionnaire.

Results

Overall results showed that students rated the seminar well. Free-text comments added that although live teaching was preferred, students found their digital and scientific competence increased through the task of writing a publication abstract on their own.

Conclusion

Digital education was not only rated well, but satisfied the students' wish for digital transformation and likewise fulfilled the national goals of competence-based education. Digital competence and skills convey data literacy in medical education and scientific education.

\section{Introduction}

With the novel coronavirus (Wang et al. 2020), medical teaching had to be transformed entirely into a completely digital curriculum in a very short period of time. Not only does the Covid-19 pandemic mean a challenge for each individual personally, but also for medical education - which evidently needs the teaching of practical skills next to theoretical knowledge. From summer term 2020 onwards, medical students in ORL were taught completely online in our department. An essential part and challenge of medical education, next to the digital transformation, is the competence-based education. A hallmark of developments in medical education, especially in Germany, is the declining interest in scientific work in medicine and declining share of young scientists - which we also wanted to address with our teaching format. In order to make a virtue out of necessity, we created the concept of a new digital scientific seminar for teaching both digital and scientific skills through a focused approach on an ORL topic.

\section{Competence-based education in medicine}


Following the CANMEDs role model, the "NKLM" has been implemented in Germany aiming at an outcome-orientated reorganization in medical studies (Frank and Danoff 2007). Digitalization is an overall action of our live and working space, and of increasing relevance not only through the pandemic: Acquiring digital skills becomes inherent part of education, and high degree of utilization usually appears when digital work becomes obligatory (Kuhn et al. 2018). This should be seen as permanent motivation to also integrate digital skills throughout medical education and thus following the goal of competencebased education.

\section{Decreasing share of medical students with interest in scientific work}

Official statistical data revealed that the share of students with scientific interest and interest in professional scientific medical careers is strongly decreasing in Germany, accompanied by a "braindrain" of most promising academic offspring mostly to e.g. UK or US. The German medical curriculum is said to have insufficient connection to scientific work, alongside with lack of career opportunities for academic offspring in medicine. We took this as our impulse to integrate teaching of scientific skills in our ORL seminar.

\section{Challenges for digital teaching in the Covid-19 pandemic in medical education}

Principally, there were several challenges to the urgently needed rapid transformation of live curricula to an entirely digital curriculum in the pandemic: lack of digital infrastructure (Kuhn et al. 2018, Freiherr von Saß P et al. 2017, Offergeld C et al. 2021), lack of established digital competences in regular teaching curricula (Kuhn et al. 2018, Offergeld et al. 2020) and the inherent problem of medical education to be linked to learning of practical skills (Rose 2020; Ahmed et al. 2020). Therefore we focused on a field where digital transformation is more easily achieved: digital work with understanding of relevant scientific publications is a necessary skill for medical professionals.

\section{Evaluation defines the quality of medical education}

Currently, quality of medical teaching in Germany is defined through standards of the German Association for Evaluation (Schiekirka et al. 2015) which are comparable to UK and US standards. Nonetheless, financial reimbursement for achievements is mainly defined by criteria and indicators of research achievements and not by achievements in teaching (AWMF). In addition, rewards for teaching excellence are more difficult because validated and standardized instruments for evaluation are missed. This stands in contrast e.g. to the fact that already by $2001,84 \%$ of the medical faculties in Germany conducted evaluations of their teaching events (Pabst et al. 2001). Against this background of importance of evaluation, we decided to decisively use it to assess the quality of our new digital scientific seminar.

\section{The Freiburg concept of digital teaching in ENT and introducing our new scientific seminar}


The Freiburg ORL curriculum was transformed into a digital teaching curriculum consisting of live lecture via Zoom, seminars (podcast/live via Zoom), online live ORL mirror examination, surgical videos (instead of live assistance in the operating room), digital outpatients section, and digital ORL learning program (Lang et al. 2020). A previous ORL seminar introduced medical students to the topic of data literacy in ORL (Offergeld et al. 2019), and its positive assessment by the students led us to seek further expansion of this topic.

\section{Objective of the seminar and aim of the study}

We introduced our new scientific seminar from the start of the "pandemic" term 04/2020 and conducted its evaluation by the end of winter term 2020/2021 in Germany (03/2021). We used a six-point scale and free-text comments for evaluation (Pabst et al. 2001). We hypothesize that scientific interest of the students determines their rating of the seminar and that the seminar increases scientific competence and interest in the students. Principally, scientific work should encourage critical thinking in students, which is a necessary competence for any further professional activity: Specifically, understanding, interpreting and judging scientific data are desired skills in medical professionals and should be promoted throughout medical education.

The objective of our seminar was to promote both digital and scientific skills of the students. Our prospective monocentric study assessed the evaluation of the digital scientific seminar.

\section{Methods}

\section{Study collective}

All students who were enrolled in ORL teaching in summer term 2020 (04/2020-08/2020) and winter term 2020/2021 (10/2020-02/2020) were asked to participate in our monocentric prospective study.

\section{Concept of the digital scientific seminar}

The seminar, or rather, teaching event (TE) started with a 15 min online podcast (summer term) or online live presentation (winter term). This theoretical introduction consisted of defining the criteria for a good scientific publication and introduction to the ORL diseases and current questions on these diseases, dealt with by the publications. The individual task consisted of 1) understanding the scientific publication, followed by 2) writing a structured abstract based on the criteria for a good abstract as learned in the presentation, thus practising a core competence of scientific writing. Hereby we wanted to address, - on the one hand side - the implementation of a digital education task in ORL teaching. On the other hand side, we wanted to foster scientific skills.

\section{Evaluation and study analysis}

Abstracts were uploaded on a learning platform called llias (van Bonn et al. 2021) and evaluation and study forms were completed online. Original abstracts were available to the students after uploading their own abstracts on the online platform. Students had the opportunity to receive individual feedback on 
their abstract by emailing to the lecturers throughout the semester. This new concept of having to understand an ORL publication first in order to write a structured abstract required the full and independent penetration of the publication content by the students. Hereby, students got prepared for further critical and focused work on publications.

The evaluation form consisted of 11 items (E) followed by eight basic questions asked through the study form (B), depicted in Table 1. Items were either rated to yes/no questions, or in a six-point likert scale. In addition, we asked for free-text comments with opinions on the course and live vs. online teaching (Table 1, Fig. 2).

\section{Statistical analysis}

Statistical analysis was performed using SPSS version 27 (IBM SPSS Statistics for Windows, Version 27.0, Armonk, NY: IBM Corporation). For analysis of two groups t-tests were performed with Levene test for equality of variance. Correlation analysis was done using Spearman's Rho. Correlation strength was defined from 0-0.3 (no correlation), 0.3-0.5 (weak positive), 0.5-0.7 (moderately positive), 0.7-0.9 (strongly positive), 0.9-1.0 (very strongly positive) or negative correlation, respectively. Level of significance was defined as $p<0.05$.

\section{Results}

\section{Study collective and scientific interest (Table 2)}

The study collective is presented in Table 2: The majority of the 265 study participants were in winter term $2020 / 2021$ ( $n=149$ vs. $n=116$ in summer term 2020). Mean age was $25.38 \pm 4.19$ years and mean study semester was $8.54 \pm 2.3$, reflecting a regular duration of studies (ORL is regularly taught in semester 8). More students were female $(55.1 \%, n=146 / 258)$. More than two-thirds of the students $(40.4 \%, n=$ $107 / 265)$ had already worked or studied before initiating their medical studies. $64.2 \%(n=170 / 254)$ had no previous experience of scientific work before participating in our scientific seminar. Although the majority declared to have no ambition for a scientific activity or career $(64.5 \%, n=171 / 248)$, most students planned a medical dissertation $(1.78 \pm 0.8, n=257$; B7), for which certain scientific skills are equally necessary.

The evaluation: Positive rating and acceptance of the seminar although live teaching is favoured (Fig. 1)

The seminar was accepted and positively rated by the students. Evaluation items were rated via a likert scale (Fig. 1; 1: "I agree completely" to 6: "I disagree completely"). Overall, the TE was rated well with an average grade of $2.22 \pm 0.88(n=261)$, and found to have a clear structure $(1.89 \pm 0.92, n=264)$ and clear definition of learning goals $(1.86 \pm 0.86, n=263)$. Students rated the relevance of the TE for their later professional activity with $2.17 \pm 0.99(n=262)$ and saw a learning effect through the TE with $2.56 \pm 0.95$ $(n=258)$. A good evaluation of the course was moderately correlated with the learning effect/growth through the TE ( $p$ (rho): $0.613, p<0.001)$. A low positive correlation with good evaluation of the TE was 
seen with view of a clearly structured TE ( $p($ rho $): 0.396, p<0.001)$ and relevance of the TE for later work ( $p$ (rho): $0.448, p<0.001)$. Students mostly agreed $(2.48 \pm 1.06 ; n=261)$ that a live TE would have increased their benefit or learning growth; this view was more supported by male students $(2.3 \pm 0.1 \mathrm{vs}$. $2.59 \pm 0.09, p=0.032$ ). With respect to later scientific work and/or ambition, students also regarded the TE as relevant $(2.56 \pm 1.02, n=164)$. The assessment of the seminar as relevant for the students' professional career and as a learning success demonstrated a successful implementation of the TE.

\section{Lasting duration of the pandemic results in lower rating of the seminar}

Significantly less students declared their ambition for a later professional scientific activity or career in winter vs. summer term $(0.77 \pm 0.04$ vs. $0.58 \pm 0.05, p=0.001)$. Students in winter term rated the TE worse vs. students from summer term: benefit through live TE vs. online ( $2.65 \pm 0.08$ vs. $2.26 \pm 0.1, p=0.001)$, learning growth through TE $(2.69 \pm 0.08$ vs. $2.38 \pm 0.09, p=0.011)$, grade for TE was worse $(2.38 \pm 0.08$ vs. $2.01 \pm 0.08, p=0.001$ ), and they regarded the TE as less relevant for later studies or work compared to their summer term colleagues ( $2.29 \pm 0.09$ vs. $2.01 \pm 0.08, p=0.023)$. To sum up, the lasting duration of the pandemic seemed to decrease students' positive rating of our digital seminar, possibly representing an increasing frustration with digital education in general as stated in some of the free-text comments.

\section{The increased processing time may reflect the demanding scope of a new teaching format}

Mean processing time for the TE was $83.88 \pm 59.69 \min (n=238)$, significantly exceeding the 60 min-time frame for which the seminar was designed: This corresponds to the new and demanding scope of the TE's individual task. Age, sex, study semester, scientific ambitions, previous work or scientific experience, were not correlated with significant alterations in processing time of the course. Processing time should be paid special attention to as it mirrors the often underestimated workload of digital teaching formats.

\section{A learning effect in the TE increased student's scientific interest}

When participants regarded the TE as valuable contribution for scientific work, they saw their interest in scientific work through the TE increased ( $p$ (rho): $0.557, p<0.001$ ). As the majority of students did not want do pursue a scientific career, correspondingly most students did not see their interest for scientific work decisively increased through the TE itself (average rating $3.36 \pm 1.09, n=263$ ). However, the more students had a learning effect, the more they regarded the TE as relevant and found their interest in scientific work after the TE increased ( $p(r h o): 0.343, p<0.001)$. The results displayed here amount to: when students found their scientific competence improved, they had an increased scientific interest.

Free-text comments: Students reflect on their increased digital and scientific skills (Fig. 2) 
In the following, most frequent free-text comments of the students are summarised (see Fig. 2). Overall, it became clear that students favour live TEs, however, they clearly see the advantages of digital education: in their view the digital scientific seminar did increase flexibility, self-organization and self-responsibility as individual competences. Students found it helpful to learn writing of a structured abstract with the possibility of individual feedback afterwards. In their view it challenged them to think through the original publication, look for the main scientific findings of it and reproduce them in an organised way. Scientific skills were increased by fostering critical thinking through the design, and digital competence was increased through the mode of the seminar.

\section{Discussion}

This prospective questionnaire study presents the evaluation by 265 students and showed the satisfactory implementation of our competence-orientated digital education format "digital scientific otorhinolaryngology seminar". Students stated that they saw their competences in self-organization, digital work and scientific work increased. Digital education was not only rated good, but students welcomed the seminar as a means of competence-based education. Results from evaluation should be used for future development of digital and scientific teaching formats.

Digital education in the Covid-19 pandemic: From the urgent need of implementing a new digital curriculum to sustainable teaching of digital skills

Digital teaching has a growing impact, which has been more articulated in the Covid-19 pandemic. This contrasts with the problem that medical teaching is dependent on successful teaching of practical skills in clinical subjects such as ORL. Lecturers must not forget that the students in clinical subjects nearly always favour live teaching, as personal medicine cannot be replaced especially during the learning process of practical skills. With lasting duration of the pandemic, digital teaching was rated worse (summer vs. winter term) in our study, possibly reflecting growing frustration of the students with digital teaching in general. In addition, expectation of students on the quality of online TEs is probably rising with lasting duration of digital teaching.

However, even in practical clinical settings, digital medicine is being on the rise, as seen by the advancements in telemedicine before and during the Covid-19 pandemic. Further fields are medical science with artificial intelligence, and robotics. Last but not least, the digital transformation in the world affects all areas of life. Digitalization of medicine takes place not only in the work of medical professionals, but also for patients, e.g. in app-based medicine. The students, who are nowadays often viewed as "digital natives" generation, also perceive the need for digital skills. Digitalization is also an expression of increased networking between different teaching formats and medical fields, and of increased potential for national and international connectedness. As international mobility has decreased, digital interconnectedness is valued higher. Digitalized learning contents can be easily exchanged on a national or, depending on the content and curricula, international scale. Not only does this apply for medical education, but also for science: In this respect, the Covid-19 pandemic has created 
new standards of international co-working and development as scientific collaborations have intensified clearly (Lee et al. 2020). Still, data literacy and digital competences are not described in the national catalogues of learning targets.

However, skills of data literacy are seen as crucial for professional careers (Ridsdale et al. 2015). In terms of our study, we see student's attitudes well reflecting advantages and possible risks of the transformation of medical education contents into digital ones. The students view digitalization as an inevitable process in the current pandemic. Risks of digitalized learning contents are clearly designated: overview and structure can be more difficult to obtain and motivation is more difficult when live formats are missing. The underestimation of processing time sheds light on an important aspect of online teaching: real workload can easily be underestimated. The risk of insufficient structure, lack of overview, and relevant highlights of contents, can be more difficult in digital teaching (Müller et al. 2018).

From a lecturer's perspective, understanding of the student is more difficult to assess in digital education. However, our study reveals that students welcome the advantages of digital education with increased potential of self-organization, self-discipline and self-responsibility- and students regard those competences as valuable for their later professional activity.

\section{Improving scientific skills}

Our study showed that digital competence can be fostered through a seminar with a focused approach of a clinical topic. Although more students stated no interest in later scientific activity, most of the students planned a medical dissertation, for which a principal set of scientific competence is equally necessary.

With increased learning growth relevance of TE was assumed to be higher. Scientific interest was increased when the TE was well rated. The future of medicine is shaped by growing intersections between science and clinical work, for which motivation of academic offspring is crucial. Opportunities for scientific activities during medical studies need to be fostered.

However, for successful and accepted implementation of digital teaching formats, cooperation with students is even more necessary (Galgut et al. 2017). As a special feature in Germany, the decentralized political structure may complicate the nationwide implementation of digital curricula (Haag et al. 2018). Hence, further studies are necessary on the opportunities of nationwide digital and scientific education curricula.

Students increased their interest in scientific work when they gained a learning effect through the seminar. Overall, there was, however, no exclusively positive feedback by the students: on average, scientific interest was not decisively increased through the seminar, that corresponds to the low fraction of students who want to pursue a scientific career in general. The evaluation of this study is the first step to improve the teaching format in cooperation with the students to follow our goal of competence-based education. They are the target audience for the professional use of digital competences and data literacy in medicine and the focus must be put on those skills needed for their later professional career. The 
Covid-19 pandemic "experience" should encourage an outcome-orientated implementation of the relevant digital skills and contents in medical education.

With all that in mind, the following criteria for a successful implementation of digital scientific education can be stated as follows:

\section{Elements for successful implementation of digital scientific education:}

- sufficient underlying structural, personal and financial base for digital transformation

- continuous evaluation and cooperation with students and feedback sessions

- balanced implementation of live and digital teaching elements

- outcome- and competence- orientated implementation with

- focus on relevant digital and scientific skills for medical professionals

\section{Conclusion}

Digital scientific education can be implemented through a focused approach in a seminar with a specific ORL topic. Students' evaluation gave a positive assessment of the new digital scientific seminar as it satisfied their wish for digital transformation, despite their general wish for live teaching. The seminar fulfilled the demands of competence-based education throughout medical studies by teaching both digital and scientific skills.

\section{Practice Points}

- Although in general live teaching is preferred, students regarded the digital scientific seminar as useful means for the acquisition of digital competence.

- The backward design of the seminar - first learning about criteria of a good scientific publication, then understanding a publication with specific ORL focus and hereafter writing its structured abstract - gave a positive assessment of strengthening student's scientific competence.

- Successful teaching of scientific competence is important in medical education in order to recruit future young scientists. It increases the interest of students for later professional scientific activity and can be used by fostering digital skills in a seminar.

\section{Declarations}

\section{Ethics approval and consent to participate}

Our study was approved by the local ethics committee (Nr. 196/20) and done in agreement with the Declaration of Helsinki (2013 version). Informed consent was obtained by all participating students prior to the study. 


\section{Consent for publication}

All authors consent for publication of the manuscript and data.

\section{Availability of data and materials}

The data was anonymized for analysis. The study data is available from all authors at the Department for Otorhinolaryngology, University Medical Centre Freiburg, Germany and is saved in a separate study folder at the internal local computer network.

\section{Competing interests}

The authors declare that no conflict of interest exists.

\section{Funding}

No external funding was received for this study.

\section{Author's contributions}

A. Rauch took the lead in writing the manuscript. A. Rauch and M. C. Ketterer analysed the data. C. Offergeld and M.C. Ketterer edited and corrected the manuscript. All authors provided critical feedback and helped shape the research, analysis and manuscript. All authors have agreed on publication of the article and carry full responsibility for its contents.

\section{Acknowledgements}

The authors thank Mrs. Karin Focke for help with administration and organization of the seminar.

\section{References}

1. AWMF online. 2020. Berlin: AWMF; [accessed 2020 April 20] https://www.awmf.org/forschunglehre/komm-evaluation-von-fl/leistungsevaluation-lehre.html

2. Daubenfeld T, Kromeier J, Heermann S, Hildenbrand T, Giesler M, Offergeld C.

3. [Traditional vs. modern: possibilities and limitations of the new lecture concept in ENT teaching curricula]. [Article in German] HNO. 2020;68(4):263-271. doi: 10.1007/s00106-020-00834-z. [Epub ahead of print]

4. Frank JR, Danoff D. The CanMEDS initiative: implementing an outcomes-based framework of physician competencies. Medical Teacher. 2007;29(7): 642-647. DOI:

10.1080/01421590701746983 
5. Freiherr von Saß P, Klenzner T, Scheckenbach K, Chaker A. [E-learning in ENT: Usage in University Medical Centers in Germany]. [Article in German] LRO. 2017;96:175-179.

6. Galgut $\mathrm{O}$, Border $\mathrm{S}$, Fenwick $\mathrm{A}$. The benefits of students as partners for developing digital literacy in medical education. Medical Teacher. 2017;39(10): 1102-1103, DOI: 10.1080/0142159X.2017.1357806

7. Haag M, Igel C, Fischer MR. German Medical Education Society (GMA), Committee "Digitization Technology-Assisted Learning and Teaching"; Joint working group "Technology-enhanced Teaching and Learning in Medicine (TeLL)" of the German Association for Medical Informatics, Biometry and Epidemiology (gmds) and the German Informatics Society (GI). Digital Teaching and Digital Medicine: A national initiative is needed. GMS J Med Educ. 2018;35(3):Doc43. doi: 10.3205/zma001189. PMID: 30186953; PMCID: PMC6120157.

8. Kuhn S, Frankenhauser S, Tolks D. [Digital learning and teaching in medical education: Already there or still at the beginning?]. [Article in German] Bundesgesundheitsblatt Gesundheitsforschung Gesundheitsschutz.. 2018; 61(2):201-209. doi: 10.1007/s00103-017-2673-z.

9. Lang F, Everad B, Knopf A, Kuhn S, Offergeld C. [Digitalization in curricular teaching: Experiences with the Freiburg ENT Learning Program]. [Article in German] Laryngo-Rhino-Otologie. 2020; doi: 10.1055/a-1334-4274

10. Lee JJ, Haupt JP. Scientific globalism during a global crisis: research collaboration and open access publications on COVID-19. High Educ. 2020; doi: 10.1007/s10734-020-00589-0

11. Müller C, Füngerling S, Tolks D. Teaching load - a barrier to digitalisation in higher education? A position paper on the framework surrounding higher education medical teaching in the digital age using Bavaria, Germany as an example. GMS J Med Educ. 35(3):Doc34. doi: 10.3205/zma001180. eCollection 2018.

12. NKLM 2.0, 2021. Berlin: NKLM [accessed 2021 May 2021]https://nklm.de/zend/menu/index

13. Offergeld C, Neudert M, Emerich M, Schmidt T, Kuhn S, Giesler M. [Mediation of data literacy in curricular education in otorhinolaryngology: watch and wait or anticipatory obedience?] [Article in German] HNO. 2019; 68:257-262 doi: 10.1007/s00106-019-00745-8. [Epub ahead of print].

14. Offergeld C, Ketterer M, Neudert M, Hassepaß F, Weerda N, Richter B, Traser L, Becker C, Deeg N, Knopf $A$, et al. ["Online from tomorrow on please" comparison of digital framework conditions of curricular teaching at national university ENT clinics in times of COVID-19: Digital teaching at national university ENT clinics]. [Article in German] HNO. 2021; 69:213-220. doi:10.1007/s00106020-00939-5

15. Pabst R, Rothkötter HJ, Nave H, Tschernig T. [Medical studies: Evaluation of teaching curricula in Medicine]. [Article in German] Dtsch Arztebl. 2001; 98(12): A-747 / B-630 / C-598.

16. Ridsdale C. Rothwell J, Smit M, Bliemel M, Irvine D, Kelley D, Matwin S, Wuetherick B, Ali-Hassan H. Strategies and Best Practices for Data Literacy Education Knowledge Synthesis Report. 2015; doi: 10.13140/RG.2.1.1922.5044. 
17. Schiekirka S, Feufel MA, Hermann-Lingen C, Raupach T. Evaluation in medical education: A topical review of target parameters, data collection tools and confounding factors. Ger Med Sci. 2015;13:Doc15. doi: 10.3205/000219. eCollection 2015.

18. Stallmach A, Bauer M, Witte OW, Siegmund B. Strategien zur Sicherung des wissenschaftlichen Nachwuches. [Strategies for securing the next generation of scientists.] [Article in German] Dtsch Arztebl. 2011; 108(8): A 380-2

19. Wang C, Horby PW, Haydeng FG, Gaoh GF. A novel coronavirus outbreak of global health concern. Lancet. 2020; 395 (10223): 470-473.

20. Rose S. Medical Student Education in the Time of COVID-19. JAMA. 2020; 323(21):2131-2132.

21. Ahmed H, Allaf M, Elghazaly H. COVID-19 and medical education. Lancet Infect Dis. 2020;20(7):777778.

22. van Bonn SM, Grajek JS, Großmann W, Bernd HE, Rettschlag S, Mlynski R, Weiss NM. [Electronic learning for otorhinolaryngology students using the content management system ILIAS]. [Article in German] HNO. 2021;3:1-8.

\section{Tables}

Table 1. Questionnaire items 


\section{Item Question}

E1a) Do you regard the TE as valuable contribution for scientific work?

E1b) Did the TE increase your interest in scientific work? (scale from 1: "I 1-6 do agree absolutely" to 6: "I disagree completely").

E2) Do you favour a live TE instead of digital teaching? Why or why not? yes/no;

free-text comment

E3) Do you think you would have learned more in a live TE ? (scale from 1: "I do agree absolutely" to 6: "I disagree completely").

E4) Were learning objectives clearly defined? (scale from 1: "I do agree absolutely" to 6: "I disagree completely").

E5) Was the teaching event clearly defined? (scale from 1: "I do agree absolutely" to 6: "I disagree completely").

$1-6$

$1-6$

$1-6$

6: "I disagree completely"

$1-6$

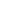

1: "I do agree absolutely" -
E6) Do you regard the content of the teaching event as relevant for your later professional activity? (scale from 1: "I do agree absolutely" to 6 : "I disagree completely").

E7) How much time did you need for the seminar? (seminar designed for $60 \mathrm{~min})$ 
B4) Study semester

B5) Education/work before studies

yes/no

B6) Scientific work before studies, e.g. publication, poster presentation,... yes/no

B7) Medical dissertation

1: "planned and initiated or already completed",

2: "planned, not started yet",

3: "maybe",

4: "not planned"

B8) Scientific activity / career planned yes/no

Legend: Evaluation and study forms were available on an online platform and completed after presentation and individual work phase. The evaluation form consisted of 11 items (E). In addition, students were asked eight basic questions (B).

Table 2: Demographics of study subjects

\begin{tabular}{|ll|}
\hline & $\mathrm{N} /$ percentage \\
\hline Participants & $\mathrm{N}=265$ total \\
& $\mathrm{N}=149$ winter term $2020 / 2021$ \\
& $\mathrm{~N}=116$ summer term 2020 \\
\hline Age & Mean $25.38 \pm 4.19$ years \\
\hline Sex & $55,1 \%$ female; $44,9 \%$ male \\
Study semester & Mean $8.54 \pm 2.3$ \\
\hline
\end{tabular}

\section{Figures}




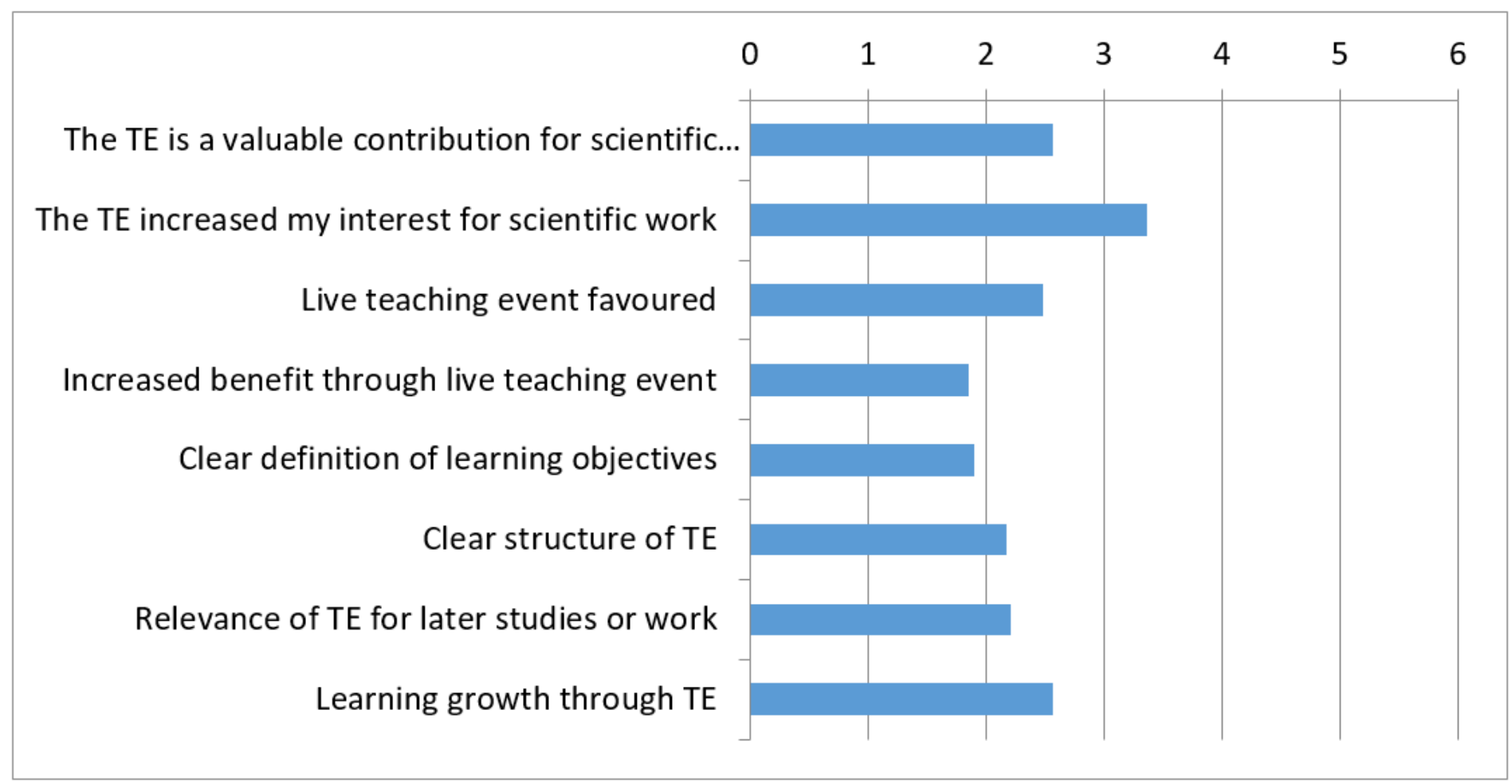

\section{Figure 1}

Likert scale: 0: I agree completely/very good, 6: I disagree completely/insufficient. 


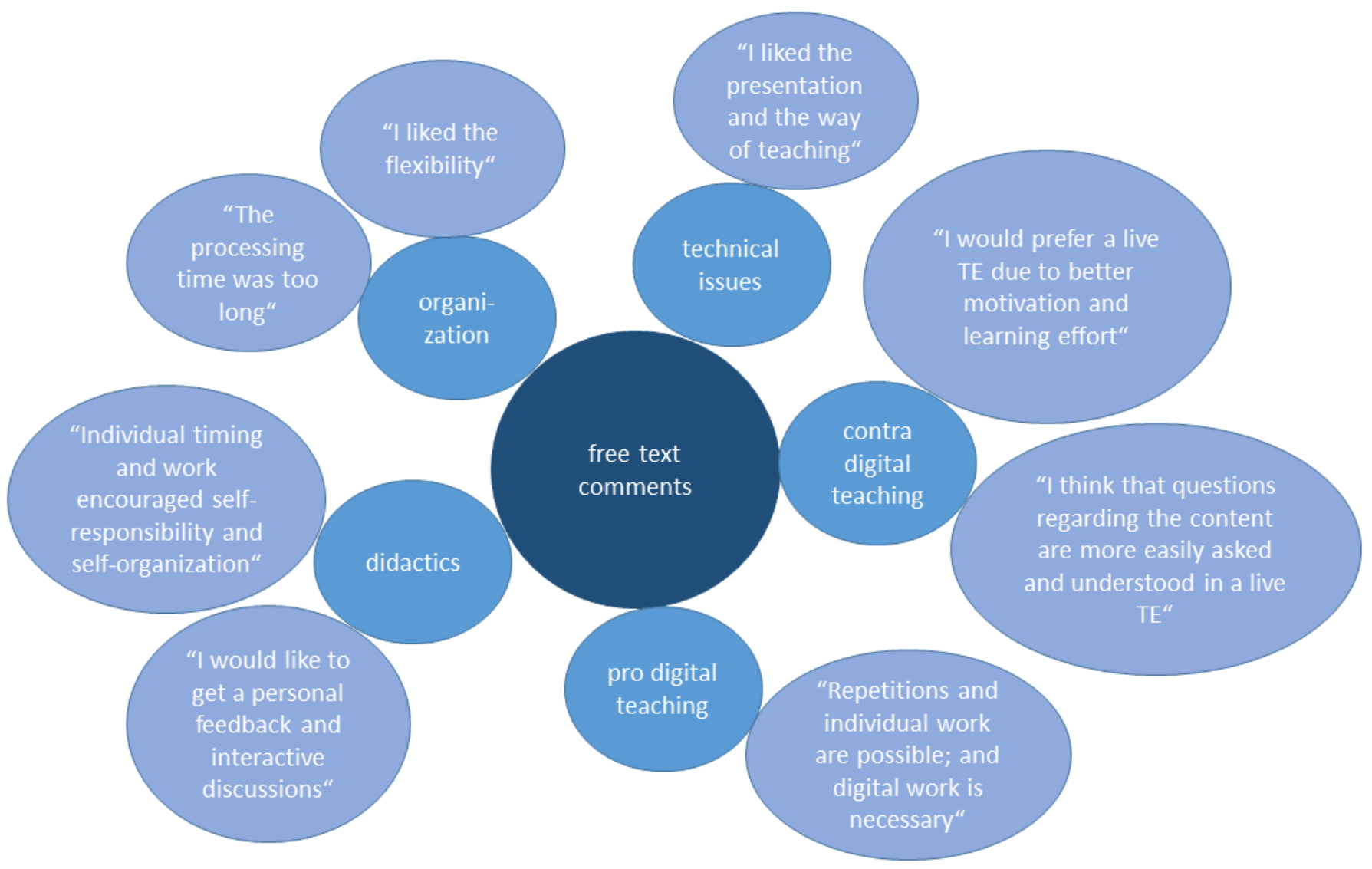

Figure 2

Free-text comments 